\title{
An Example of a Country Assessment: Desertification Mapping in Italy
}

\author{
Riccardo G. Boschetto*, Marco Di Leginio, Anna Luise \\ ISPRA - Istituto Superiore per la Protezione e la Ricerca Ambientale \\ Via V. Brancati 48, 00144 Roma, Italy
}

Received: 23 December 2009. Accepted: 14 June 2010.

\begin{abstract}
Desertification is the result of human induced land degradation which can be accelerated under severe drought conditions, and can occur under very diverse climatic conditions. Actually, studies have been conducted on assessing the vulnerability to desertification in Italy at national and regional level and they are based on different methodologies to carry out maps. These methodologies are developed by combination of different climatic, soil, vegetation, and socio-economic attributes useful to estimate pressure on land and state of soil and vegetation. This study is aimed at sketching the methodologies used in the creation of the current available maps of the risk of desertification in Italy and the state of the art of the mapping tools as well as some limits of them: firstly, a complete absence of bias in each indices of the algorithm which gives vulnerability index, and secondly the extreme variability of indices in relation to the degree of precision from national to local scale.
\end{abstract}

Key-words: desertification mapping, dismed, ESA index.

\section{Introduction}

Desertification does not refer to the expansion of existing deserts. It occurs because dryland ecosystems are extremely vulnerable to over-exploitation and inappropriate land use (UNCCD, 2005). This complex phenomenon reduces the soil fertility involving ecological and economic processes that characterise the environment at different geographic scale. Nowadays, the most widely accepted definition of desertification is the one given by the United Nation Convention: it defines desertification as "land degradation in arid, semi-arid and dry sub-humid areas resulting from various factors, including climatic variations and human activities". The complexity of this phenomenon represents a limitation for the scientific community either to develop a unique methodology or to harmonize the already existed methodologies in order to have reproducible method to assess and control the land vulnerability and desertification processes. Thanks to an homogeneous procedure, it will be easier to arrange a common approach to carry out efficient action plans at national and local level. As the matter of fact, the heterogeneity of cause-effects relationships and the interconnections between desertification factors and human activities prevent to find an efficient methodology to evaluate the desertification process state (Alcamo et al., 2007). Considering the multiplicity of statistical sources used in geographical studies, it is hard to provide sound information on desertification trends also in more developed countries. This article aims at pointing out the current state of mapping on desertification and drought starting from the most recent mode based on DISMED methodology (DISMED, 2003), which is inspired by the one developed in the framework of the MEDALUS project (Mediterranean Desertification And Land Use) (European Com-

* Corresponding Author: Tel.: +39 06 50072566; Fax: +39 06 50072657. E-mail address: riccardo.boschetto@isprambiente.it. 
mission, EC, 1999). Sensitivity to the desertification of the different spatial homogeneous units is defined by an index called ISD: Index of Sensitivity to the Desertification, obtained from the geometrical average of three indexes of the soil quality, climate and vegetation leaving out land planning and socio-economic aspects. Besides, the paper explains the results obtained in terms of desertification mapping using the earlier methodology, built up over few indices related to main factors involved in desertification process, which has been more appropriated to produce an early evaluation of Desertification Sensitive Areas (DSA) at a national or regional scale.

\section{Materials and methods}

In Italy, previously, studies regarding mapping the desertification vulnerability have already been carried out in the scope of maps produced at global and continental scales (DISMED ${ }^{1}$ Project - Desertification Information System for the Mediterranean, 2003).

According to the results of the assessment, based on a methodology developed within the DISMED Project (the assessment only takes into account causal factors such as soil properties, climate and vegetation; socio-economic indicators are not included), Italy, together with Spain, Portugal and Greece, is one of the countries in Europe most affected by desertification and drought. The main results of this project have been summarized in Table 1, they are:

- in all Europe country, Spain is the one most affected by desertification problems, followed by Italy, Greece and Portugal;

- Italy has the highest values of sensitivity area placed between the range from medium to low sensitivity class;

\footnotetext{
${ }^{1}$ A European Project has aimed at improving the capacity of national administrations of Mediterranean countries to effectively program measures and policies to combat desertification and the effects of drought. Th European Environment Agency (EEA) provided technical and institutional assistance and overviewed the coordination of the different national institutions. The Italian National Counsel of Research (CNR) and Applied Meteorology Foundation (FMA) provided scientific assistance. The UNCCD Secretariat has played a role of executing agency.
}

Table 1. Percentage of sensitivity area to desertification resulted by DISMED project

\begin{tabular}{lrrrr}
\hline & Portugal & Spain & Italy & Greece \\
\hline Area $\left(\mathrm{km}^{2}\right)$ & 91.858 & 505.988 & 301.401 & 131.992 \\
Very high & 0 & 0 & 0 & 0 \\
High & 2,51 & 8,53 & 3,07 & 5,83 \\
Medium & 28,88 & 48,29 & 32,15 & 36,88 \\
Low & 64,70 & 39,93 & 64,11 & 56,27 \\
Total sensitivity * & 96,10 & 96,75 & 99,93 & 98,98 \\
Very low & 3,90 & 3,25 & 0,67 & 1,02 \\
\hline
\end{tabular}

*Sum of percentage of classes from "Low" to "Very low".

- absence of very high, that is irreversible desertification sensitivity national areas.

Figures 1 and 2 show that nearly $3 \%$ of the national territory presents a high sensitivity to desertification and more than $32 \%$ a medium sensitivity degree. Entirely, more than $35 \%$ of
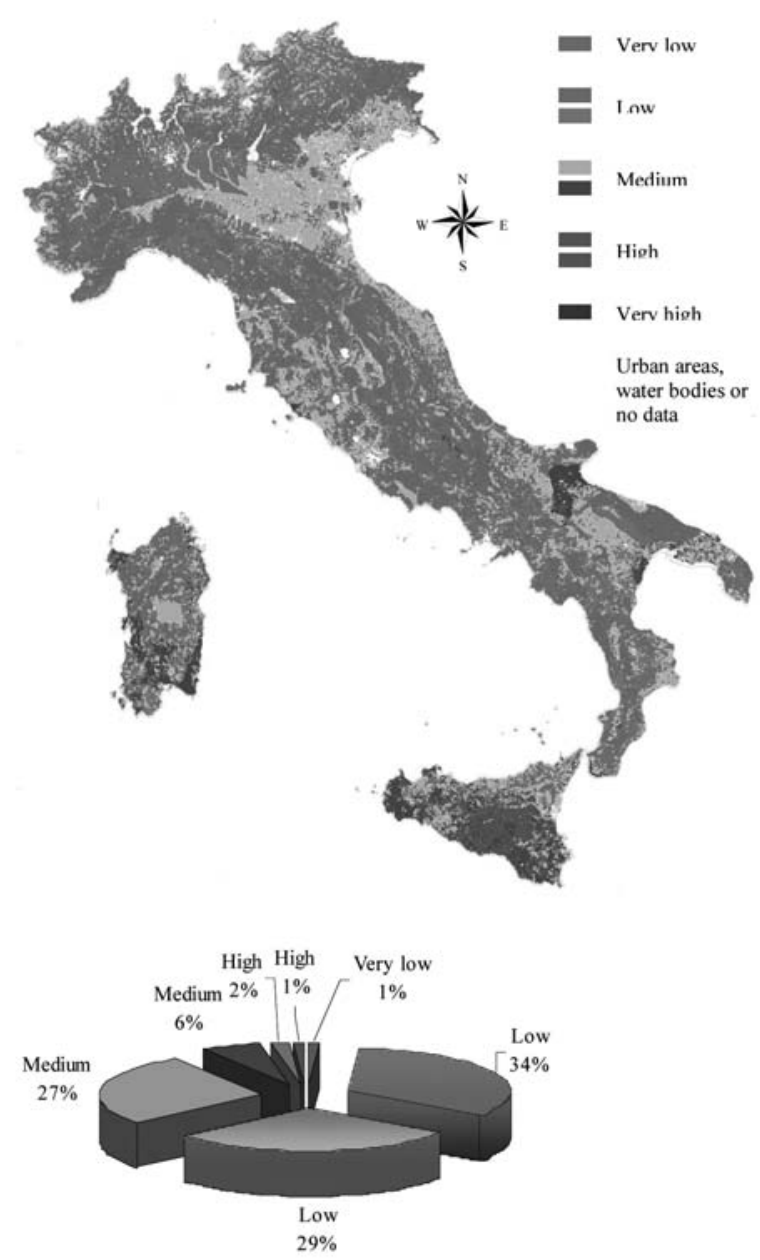

Figure 1. Desertification sensitivity Italian map realized during first DISMED project. 


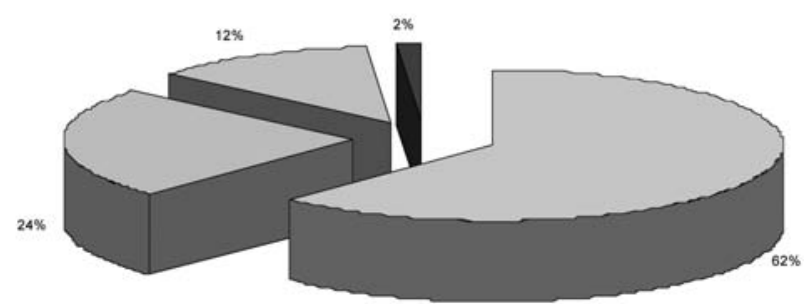

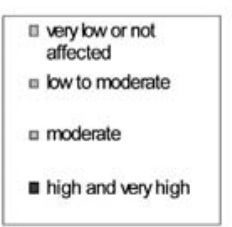

Figure 2. Sensitivity to desertification according the updated DISMED project. the national territory presents high or medium sensitivity, for different reasons, and only less than $1 \%$ could be declared not sensitive at all; the areas most affected by desertification process are the southern regions (Sicilia, Sardegna, Puglia, Basilicata and Calabria), but severe problems are present also in the north part of the country (especially along the Po valley).

A step forward it has been made, recently, in order to update DISMED database (EEA, 2008) using data sources from Corine Land Cover 2000 and European Soil database (version 2) and the results are shown in Figure 2 and Table 2.

According to the analysis, approximately $2 \%$ of the territory, corresponding to nearly 500.000 ha, currently shows a high sensitivity to desertification and drought. The part under concern increases to about four million ha if moderate sensitivities are also taken into account (see map). The situation is most serious in most of Sicily and in some areas in Sardinia and other southern regions. Predicted changes in climate are expected to increase the vulnerability in these regions (IPCC, 2007).

A previous map of Italian areas prone to desertification (Fig. 3) was carried out, before DISMED project, according to NAP (National Action Programme) in order to provide tools for the monitoring and assessment of vulnerable areas.

Table 2. Areal distribution of Sensitivity to Desertification Index.

\begin{tabular}{|c|c|c|c|}
\hline $\begin{array}{l}\text { SDI } \\
\text { thresholds }\end{array}$ & $\begin{array}{c}\text { Total } \\
\text { area } \mathrm{km}^{2}\end{array}$ & $\begin{array}{c}\text { Percentage } \\
\%\end{array}$ & Sensitivity index \\
\hline$<1,2$ & 184776 & 62,55 & $\begin{array}{l}\text { very low or not } \\
\text { affected }\end{array}$ \\
\hline $1,2-1,3$ & 69503 & 23,53 & low to moderate \\
\hline $1,3-1,4$ & 36645 & 12,40 & moderate \\
\hline $1,4-1,5$ & 4501 & 1,52 & high \\
\hline$>1,6$ & 0 & 0,00 & very high \\
\hline Total area & 295425 & 100,00 & \\
\hline
\end{tabular}

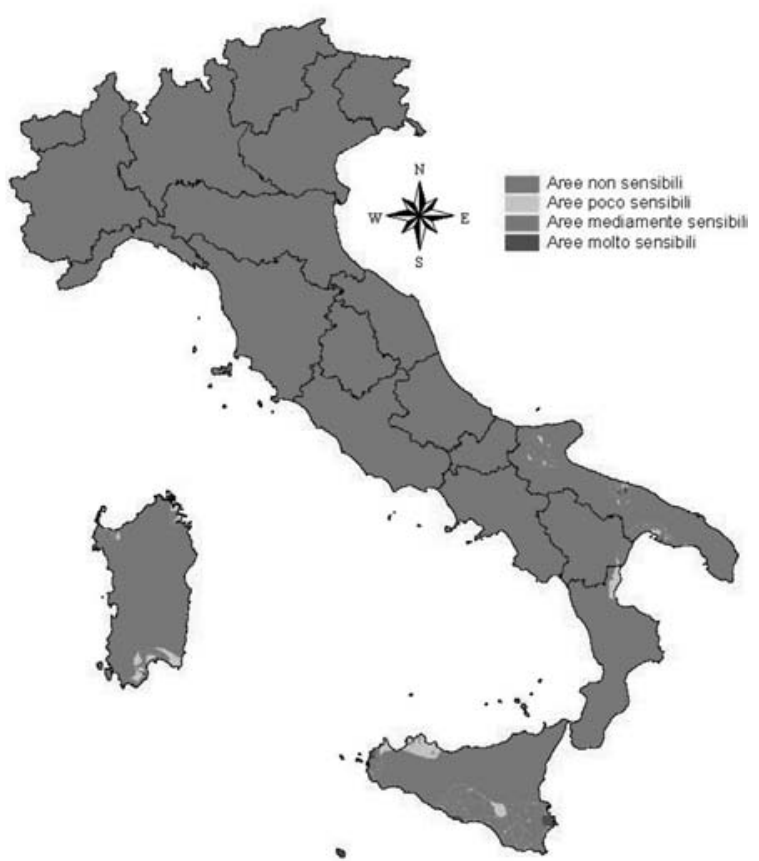

Figure 3. National Map of Italian Areas Prone to Desertification.

The map (Presidenza del Consiglio dei Ministri, DSTN, 1999) was obtained combining four different indices reflecting specific processes related to desertification. The used indices were: - aridity index, defined by means of the relationship between the average yearly precipitation and the average yearly potential evapotranspiration;

- soil characteristics index, related to the pedoclimatic classification of Italian territory (dependent on soil and its biotic cover);

- land use index, obtained by means of a reclass of the original Corine Land Cover classes;

- demographic variation index, defined as percentage of variation of the population from 1981 to 1991, at a communal scale.

Furthermore, a number of local authorities 


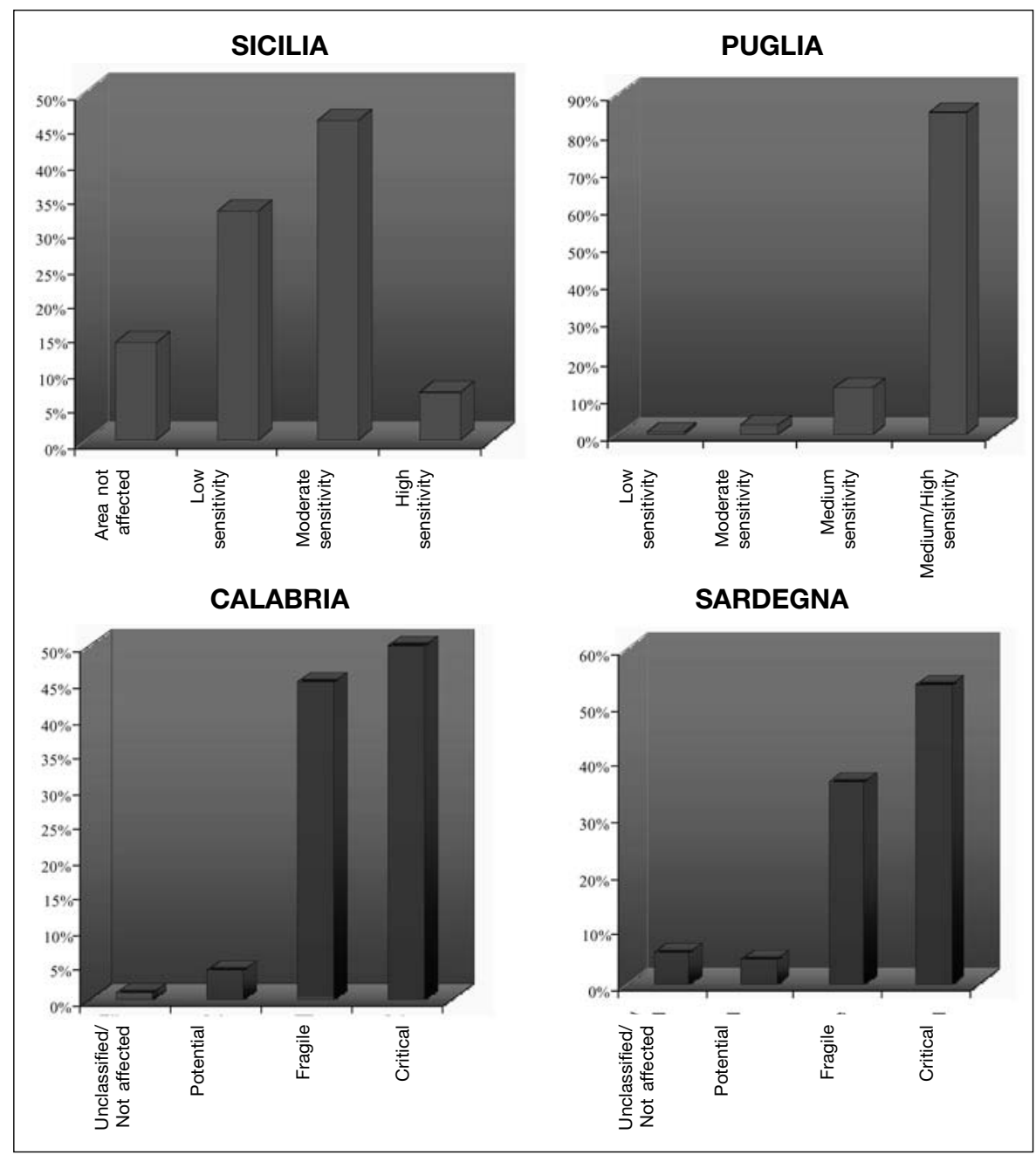

Figure 4. Results of desertification maps elaborated by local authorities. Calabria and Sardegna maps have been developed using Medalus methodology while Sicilia and Puglia have been carried out using the term "sensitivity" which means the degree of response of ecosystems to external agents impacts (i.e.: biological, geodynamic, climatic, etc.) (Motroni et al., 2004; ARPACal, 2005; Giordano et al., 2002; Montanarella et al., 2000).
(Regions and Provinces) carried out desertification assessment at local scale utilizing ESA methodology (Motroni et al., 2004; ARPACal, 2005; Giordano et al., 2002; Montanarella et al., 2000). The results are actually at validation stage; we have to take into account that ESA methodology leave the user to determine sensitivity classes with a certain degree of freedom, and therefore with some concerns on the data and information homogenization and comparisons (Fig. 4). A summary of case studies are explained hereafter.

\section{Case study: Calabria}

According to the Institutional issue the Environmental regional agency of Calabria (ARPACal) has developed some projects aimed at studying desertification processes focusing on the following thematic activities:

- monitoring and control of drought phenomenon;

- individualize a correlation with biotic component;

- bio-climatic and fito-climatic characterization of the country region;

- development of suitable indicators;

- implementation of forecasting models.

Key indicators for the estimation of soil capacity to resist degradation processes will be found through the MEDALUS methodology (MEditerranean Desertification And Land USe: European Commission, 1999), which allows the assessment of desertification risks on a regional scale. Indicators have been grouped into four classes, on the basis of soil quality (SQI), cli- 
mate quality (CQI), vegetation quality (VQI) and management quality (MQI). Each index has been classified into three levels (high, moderate and low) according to the MEDALUS classification, and they have been entered into and employed by a Geographical Information System (GIS), which define the different layers depending on the quality index considered. In this way, the contribution of each quality index has been defined and intervention and mitigation proposals developed through the description of the main sectors (soil protection, sustainable management of agricultural resources, decreased impact of production activities and territory re-equilibrium), allowing the definition of criteria used to limit the effects of the degradation and to allow correct land use. According to this methodology ARPACal has carried out regional maps of areas susceptible to desertification at 1:250.000 scale.

The final step has comprised the matching of the physical environment qualities (soil quality, climate quality, vegetation quality) and the management quality for the definition of the various types of Environmetally Sensitive Aareas to desertification. A unique ESAs Index (ESAI) was calculated as geometric mean value as following:

$$
E S A I=(S Q I \times C Q I \times V Q I \times M Q I)^{\frac{1}{4}}
$$

At this end four different types of sensitive areas to desertification were classified:

Type A. Areas already highly degraded through past misuse, presenting a threat to the environment of the surrounding areas. For example, badly eroded areas subject to high runoff and sediment loss. This may cause appreciable flooding downstream and reservoir sedimentation. These are "critical ESAs" and in Calabria comprises less than $50 \%$ of the areas assessed (Fig. 4).

Type $B$. Areas in which any change in the delicate balance of natural and human activity is likely to bring about desertification. For example, the impact of predicted climate change due to greenhouse warming is likely to enhance reduction in the biological potential due to drought causing areas to lose their vegetation cover, subject to greater erosion, and finally shift to the Type A category. A land use change, as for example, a shift towards cereals cultiva- tion, on sensitive soils might produce immediate increase in runoff and erosion, and perhaps pesticide and fertiliser pollution downstream. These are "fragile ESAs" and in Calabria is around $45 \%$ of the areas assessed.

Type $C$. Areas threatened by desertification under significant climate change, if a particular combination of land use is implemented or where offsite impacts will produce severe problems elsewhere, for example pesticide transfer to down slope or downstream areas under variable land use or socio-economic conditions. This would also include abandoned land which is not properly managed. This is a less severe form of Type $\mathrm{B}$, for which nevertheless planning is necessary. These are "potential ESAs". In Calabria the potential ESAs are under $10 \%$ of the area evaluated.

Type $D$. Areas with deep to very deep, nearly flat, well drained, coarse-textured or finer soils, under semi-arid or wetter climatic conditions, independently of vegetation are considered as "non-threatened by desertification". Calabria presents around $2 \%$ of the areas not completely affected to desertification.

The results of desertification maps elaborated by local authorities in Calabria region can be summarize as following:

- ionic coast is significant more sensitive to desertification manly the three major areas are: the coast line long the Sibari plan till the northern boundary;

- the southern coast line from Reggio Calabria to Capo Spartivento. These areas are valuated as critical ESAs. This is a peculiar characteristic of the ionic coast line due to the combination of the risk to drought phenomena combining with the idrogeologic collapse.

\section{Conclusions and discussion}

There are various inadequacies associated with the methodologies and mapping structure decribed. One problem is that the relationship between the climate, the physical environment, socio-economic factors (quality indices), land use and land degradation or desertification is mediated and affected by at least the following: available technology, market mechanisms, historical tradition, inertia, culture, and various economic 
factors such as subsidies which have not been taken fully into consideration. All these aspects are currently invisible to the methodologies and are not directly present in any of the available data; although their integrated effects are somewhat present in the current patterns of desertification that the quality index of the methods is being asked to represent.

Major differences exist in quality, scale, and aggregation between existing physical environmental-climatic and socio-economic data presenting a serious obstacle to straightforward integrated desertification methodology. Physical models of land degradation and desertification generally operate at a much more detailed spatial and temporal scale compared to existing socio-economic models. Additionally, socio-economic data generally could be relates to irregularly shaped zones that are historically unstable and subject to continuous change, whereas physical environmental-climatic models tend to use and produce data in regular structures although at a range of different scales. Hence, the most practical difficulties in assembling every type of data set needed for a suitable desertification assessment can be classified as:

- data quality is immensely variable and it seems necessary to weight the quality indices to reach a bias average value for desertification vulnerability;

- the spatial data are not referenced in a standard format, so the methodologies used can be considered not reproducible;

- major mapping pre-processing was necessary in attempting to represent the required data from multiple different sources in terms of a single consistent spatial framework; none of the socio-economic data exist at anything approaching the same geographical scale as the physical and climatic data.

\section{References}

Motroni A., Canu S., Bianco G., Loj G. 2004. Carta delle aree sensibili alla desertificazione (Environmentally
Sensitive Areas to Desertification, ESAS). Relazione Tecnica. Servizio Agrometeorologico Regionale per la Sardegna, realizzato per conto della Regione Autonoma della Sardegna.

Alcamo J., Moreno J.M., Nováky B., Bindi M., Corobov R., Devoy R.J.N., Giannakopoulos C., Martin E., Olesen J.E., Shvidenko A. 2007. Europe Climate Change 2007: Impacts, Adaptation and Vulnerability. Contribution of Working Group II to the Fourth Assessment Report of the Intergovernmental Panel on Climate Change, Parry M.L., Canziani O.F., Palutikof J.P., van der Linden P.J., Hanson C.E. (eds.), Cambridge University Press, Cambridge, UK, 541-580.

ARPACal 2005. Carta delle aree sensibili alla desertificazione in Calabria - scala 1:250.000. Progetto Desertnet.

DISMED 2003. Information on the DISMED project is available on the web at http://dismed.eionet.europa.eu/.

EEA 2008. Mapping sensitivity to desertification (DISMED). Working paper on methodology. Version 2, January 2008. Prepared by: Francisco Domingues and Jaume Fons-Esteve, ETC/LUSI - Autonomous University of Barcelona.

European Commission (EC), 1999. The MEDALUS Project Mediterranean desertification and land use. Project report, Kosmas C., Kirkby M., Geeson N. (eds.). European Union 18882, 31-47 ISBN 92-8286349-2.

Giordano F., Giordano L., Grauso S., Iannetta M., Rossi L., Sciortino M., Bonati G. 2002. Individuazione delle zone sensibili alla desertificazione nella regione Siciliana. In: Valutazione e mitigazione della desertificazione nella Regione Sicilia: un caso di studio. Monografia Enea, Ministero dell'Ambiente e della Tutela del Territorio, Prov. Regionale di Agrigento, Comune di Licata, 27-47.

Montanarella L., Baracchini R., Rusco E. 2000. Programma d'Azione per la Lotta alla Siccità e alla Desertificazione. Indicazione delle aree vulnerabili in Puglia. EUR 19590/IT.

Presidenza del Consiglio dei Ministri, Dipartimento per i Servizi Tecnici Nazionali (DSTN), 1999. National Preliminary Map of Italian Areas Prone to Desertification. National Action Programme.

Carnemolla S., Drago A., Perciabosco M., Spinnato F. 2002. Metodologia per la redazione di una carta in scala 1:250.000 sulle aree vulnerabili al rischio di desertificazione in Sicilia.

UNCCD 2005. Explanatory Leaflet, http://www. unccd.int/convention/text/leaflet.php. 